\title{
Intelligent products - a step towards a more effective project delivery chain
}

\author{
Mikko Kärkkäinen $^{*}, 1$, Jan Holmström ${ }^{1}$, Kary Främling ${ }^{1}$, Karlos Artto ${ }^{2}$ \\ Department of Industrial Engineering and Management, Helsinki University of Technology, \\ P.O. Box 9500, FIN-TKK 02015 Helsinki, Finland
}

\begin{abstract}
International projects present really difficult logistics challenges. In international investment projects, a vast number of individualised deliveries has to be managed through a large supply network in a tight timeframe. This article investigates how the logistic challenges of international projects can be solved by utilising advanced web technologies and product identification. The paper presents a control system being built at Helsinki University of Technology, which is based on distributed programming, and wireless identification technologies. The aim of the system is to change the controlling mechanisms of project deliveries by giving the deliveries themselves the means with which to control their route. This enables the material flows in the project delivery chains to be controlled from the inside of the material flow itself.
\end{abstract}

(C) 2002 Elsevier Science B.V. All rights reserved.

Keywords: Project management; Project delivery chain; Identification technology; Distributed programming; Information management

\section{Introduction}

International projects have presented themselves as one of the most formidable logistics challenges. This can be seen in an ever-growing interest in supply chain management in the project industry [1-3]. In global

\footnotetext{
* Corresponding author.

E-mail addresses: mikko.karkkainen@hut.fi (M. Kärkkäinen), jan.holmstrom@hut.fi (J. Holmström), kary.framling@hut.fi (K. Främling), karlos.artto@hut.fi (K. Artto).

${ }^{1}$ Mikko kärkkäinen, Jan Holmström, and Kary Främling are researchers at Helsinki University of Technology. Their work includes developing flexible control methods systems for logistics and supply chain management.

${ }^{2}$ Karlos Artto is the professor of international project oriented business at the Helsinki University of Technology. Professor Artto possesses a wealth of practical experience on the management of international project business, and is currently working on developing project delivery chain management.
}

business, materials and components are sourced world-wide from many different suppliers, manufactured and assembled in different continents, and sold in many different countries ([4], pp. 18-19). Large investment projects form one especially difficult case of global business. In them, suppliers from all over the world usually deliver specific parts to the project site, at which the constructor assembles the project [1].

A project delivery chain is defined as an entity formed by several interlinked projects that have the aim of delivering a complete project product to the end customer [1]. The customer's investment project is always the downstream end point of a project delivery chain [1]. According to this definition, each project is interpreted through its project product (deliverable), which emphasises the product- and logistics-oriented nature of the delivery chain. However, another view that can be taken of a project delivery chain is that of a chain of interlinked customers and suppliers [2]. This 
view adopts the organisational network and value chain perspectives. Suominen [3] provides a more detailed analysis of the nature of the project delivery chain from, in particular, the logistics and business network viewpoints.

The aim of this paper is to present a new way of controlling material flow in a large investment project. The paper is based on a control system that is being built at the Helsinki University of Technology. The system is currently in a state where most technological solutions have been tested separately, so the first pilot systems are expected to be operational in 2002.

The first section of the paper discusses the characteristic challenges of supply chain management in large international investment projects. The second section introduces the solution being built at HUT. In the third part, the functionality of the system is examined, while in the final section, the costs and benefits of the system are estimated and future development needs are discussed.

\section{Challenges of project delivery chain management}

Besides the normal problems of difficult co-ordination derived from the high complexity of global supply chains ([4], p. 109), investment project deliveries present challenges peculiar to them. In this section, the characteristic challenges of international investment project deliveries are discussed.

Investment projects consist of a set of product individuals. Product individuals are products that (whether customised or mass-produced) have a specific, clearly defined place in the resulting construction, are identifiable at individual item level, and have to be handled as individuals. In investment projects, even the engineering of product individuals is often the responsibility of equipment manufacturers [1].

The fundamental challenge of international investment project deliveries lies precisely in the customised nature of project deliveries. The product individuals have to be treated in an individualised manner throughout the supply chain. Their specification, quantity, and delivery time are defined in the project plan. For example, in producing and delivering a paper machine, its parts have to be treated as individuals from the subcontractor stage all the way through the operation and maintenance of the system [1].

The great number of individual deliveries to the project site presents another major challenge in large investment project deliveries. One has to develop an effective means of operating with the great number of deliveries, even though they are product individuals. Unnecessary costs in, for example, reception or handling the deliveries add up to significant costs in the project as a whole, as the number of individual deliveries increases. For example, a typical investment project in the paper industry consists of some 1500-2000 individual deliveries [1].

A third challenge of international investment project deliveries derives from the large number of suppliers participating in the project. There are can be as many as 150 primary suppliers in a project, and there are often over a thousand suppliers overall if secondary and tertiary suppliers are also taken into account [1]. The information linked to each product individual of the project has to be managed throughout the whole supply chain. However, it is difficult to manage the information because the number of companies in the supply network of international investment projects is so large. At the moment, the information loss of project components after the delivery is a severe problem. The problem is caused by the fact that all companies in the project delivery chain store the information concerning product individuals, but usually have different product codes. Also, when the information is sent through information networks as transactions between network members (e.g. via an EDI-connection), there are often problems in matching the information flow to the physical deliveries [5].

Deliveries to the project site are time-critical. This is a fourth specific challenge of international project deliveries. The challenge is to time deliveries in an uncertain environment to arrive late enough not to cause severe storage problems, but in time so as not to hinder the carrying through of the project. Deliveries arriving at the project site ahead-of-time cause unnecessary trouble. Also, unnecessary investment in secure storage space is needed to store ahead-of-time deliveries, and the goods have an increased risk of being lost or stolen. International shipments of goods are subject to unpredictable delays due to bad weather, bureaucratic delays related to customs and documentation, and occasional labour strikes [6]. 
If the deliveries are late due to the delays, the carryingthrough of the project may suffer. This is why just-intime (JIT) deliveries are not used or advised by experts in investment projects ([7], pp. 241-241; [8]).

\section{Solving the challenges with product identification and advanced web technologies}

To recapitulate, the fact that a large number of product individuals has to be managed from the source of supply to the project site through a complex project delivery chain in a tight timeframe, without losing information regarding the product individuals, presents particular challenges characteristic of large international investment projects.

At Helsinki University of Technology, we are building a system for controlling the deliveries of international investment projects. The solution aims at relieving the logistic problems of international investment projects by providing intelligence to the delivery systems. The idea of the system is to integrate the flow of information with the material flow itself, and to build information services that are flexibly operated in an open network.

The great number of product individuals that are delivered to a specific project demand effective processes for handling both the physical deliveries themselves, and the information regarding the deliveries. Both the product individual and the information have to be handled in an individualised manner. To increase the efficiency and to minimise errors in operations, manual phases in handling and data input should be minimised [9]. In the HUT system, the deliveries can communicate their identity and necessary handling instructions directly to the information systems without human intervention. This enables supply chain members to process the product individuals efficiently, even when they have to be handled in an individualised manner [10].

It is vital to be able to manage the product-related information through the whole life-cycle of the product individuals. Company specific (often paper based) data storage has proved to be an unfeasible way of managing the information; information should rather be managed process-wide with electronic means of data storage ([11], pp. 104-106 and 119121). In the HUT system, information is managed in an open network that enables all supply chain members access to the information. This enhances the system both by enlarging the scope and increasing the usability of the system.

The problems with the time criticality of the delivery of product individuals would be relieved if the project contractor had the capability of tracing deliveries to gain knowledge of their delayed arrival (or, even better, if the contractor could get a proactive announcement of a delay). This would enable the project plan to be updated by taking into account the delay of that particular delivery. Thus, the drawbacks of delayed shipments could be greatly reduced. Then shipments could also be sent with a smaller safety-margin, which would result in shorter leadtimes and less trouble with storage and security on the project site. Tracking services are built into the HUT system. The system collects information about the progress of product individuals in the supply chain, and can inform the contractor of delays or loss of a product individual.

\subsection{Effective handling of product individuals}

The basic idea in the distributed supply chain information system at HUT is that product individuals are given their own identity (content and delivery terms) and the means to communicate this information to logistics service providers. Then the product individuals themselves can be transformed into their own agents, which may assemble the logistics services they need for fulfilment.

The principles of the HUT system for effective handling are illustrated in Fig. 1.

The solution to the problems of the project delivery chain rests in the control orientation of material flow. The product individuals in the project delivery chain themselves say where they are going, and how they should be handled. The result is that deliveries are no longer controlled from the outside using company specific databases which interchange information in predefined transactions. Rather, deliveries are controlled from the inside-out, that is, within the material flow itself.

To move to inside-out control of project deliveries, two things are needed. Firstly, the product individuals have to know what needs to be done with them-to what products they belong, where and when they need 


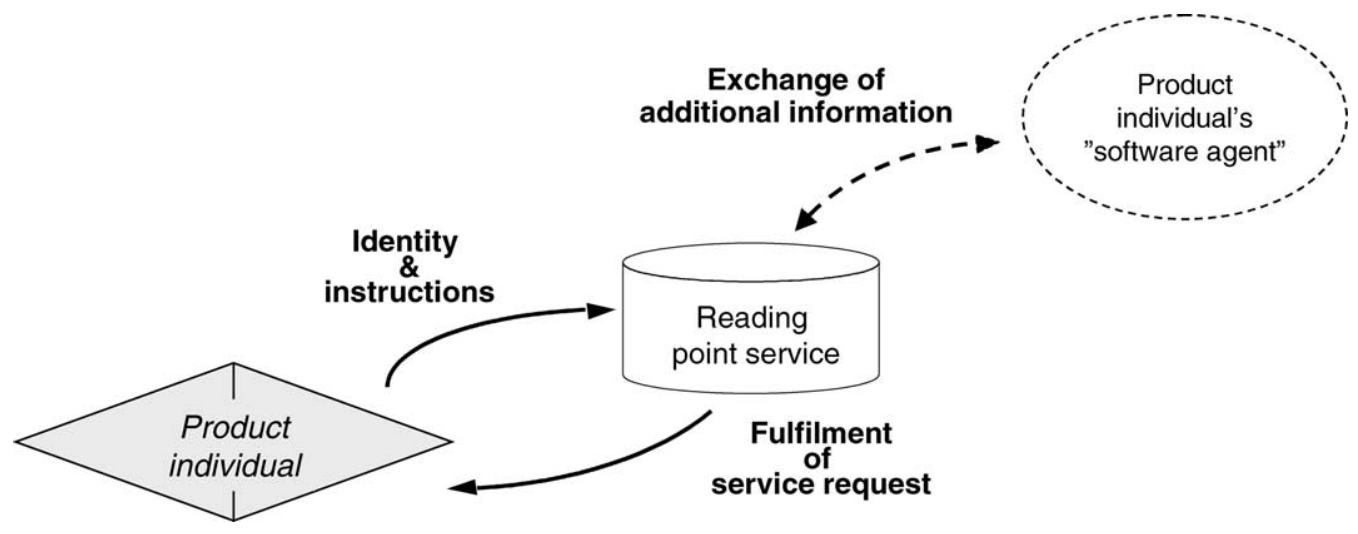

Fig. 1. The principles of the HUT system for effective handling of product individuals.

to be delivered, and how they should be handled. Secondly, the product individuals have to be able to communicate the information to different supply chain members.

In the HUT system, the product individuals are given their own identity by using radio frequency identifiers. These identifiers are called transponders or, briefly, tags, and communicate with readers using radio waves [12]. Every radio frequency identification (RFID) tag has a globally unique identification code, and can therefore be used to identify product individuals in their different supply chain phases.

Common RFID tags provide from 256 bits to several kilobytes of read/write memory [13-15]. The most essential information for logistics execution is stored in the tag's memory. Also, the identification code of a tag is used as a reference to a database that contains all the information related to the product individual (or references to where additional information can be found). In this respect, the HUT system closely resembles the systems that the Auto-ID Center at MIT is building for consumer products [16].

RFID technology was selected to be the identification technology used in the system, because it lends to efficient handling as items can be identified effortlessly and as they move. This is because RFID tags do not require a line of sight in order to be read, they can be read through non-metallic materials and about 60 tags can be read simultaneously [17-19]. The tags can also be used in the whole supply chain as they endure wearing environments well [20].
Bar coding can also be used to give delivery items an identity of their own and to connect to databases for information concerning the delivery [21]. Also, bar code identifiers are significantly cheaper to produce than RFID tags. However, the drawbacks of bar coding disable it from being a good solution to the problems of international investment project deliveries. Bar codes most often require manual handling in order to be read $[17,18]$, and often lose their readability through successive handling and in difficult environments [22,23]. Also, it is not possible to change their content after they have been printed, so their information content cannot be updated dynamically [24].

A significant problem with RFID tags is that they always require a reader in order to communicate with the system [12]. Bluetooth chips would be accessible without having to pass through a specific reader device, because of its ability to proactively establish a connection with the information networks [25]. This ability would be valuable in, for example, preventive maintenance. Nevertheless, Bluetooth does not offer a suitable identification technology for industrial projects. The biggest obstacles are its price, between US\$ 20 and 30 in large volumes, and its need for energy $[26,27]$. Also, at the moment there is not a chipvariation available that can sustain harsh industrial environments.

To ensure the success of communication between the product individual and the supply network member, a standard code of communication is needed. The standardisation of RFID technologies is still underway, and proposals to solve the issue are pending [13,28,29]. 


\subsection{Network infrastructure to share information} and provide services

In the HUT solution, product individuals act as an information media between supply chain members. The distributed supply chain information system uses a kind of peer-to-peer architecture. Communication between software components located at different places in the supply network is made possible by distributed software technologies: Jini [30], Remote Method Invocation (RMI) [31] and other solutions related to the Java programming language. For nonJava services, techniques like Corba [32] and XML documents are the solution.

The principles of information sharing and service provision in the peer-to-peer network are illustrated in Fig. 2. In such a peer-to-peer network, it is common for the same software component to need to act sometimes as a client, sometimes as a server and sometimes as both simultaneously. Using distributed software techniques like RMI and Corba instead of classical client-server technology greatly simplifies the creation of such dialogues between software components on different computers.

Different services can be built into the peer-to-peer network. One example of a valuable service is a service that traces the progress of product individuals in the supply network, communicates this information to the project plan, and passes the (possibly changed) planned delivery dates to the product individual. In the tracking service, when a product individual passes a reading point in the network, the reader that identified the product individual updates the tracking information of the product individual to the network address read from the product individual itself. The information transmitted by the reading point at least contains the identification of the product individual, the physical location of the reading point and the time of the pass. The tracking service can then communicate with the project plan service if needed; this checks whether any changes to the project plan need to be made. If changes to the planned delivery time of the product individual are made, the tracking service passes them to the reading point service, which can then update it to the product individual and eventually identify a new routing that is more suitable for the new delivery time. Information exchange in other services (e.g. maintenance) follows the same principles.

\subsection{A solution to both handling and information sharing problems}

As presented earlier, associating information with the product individuals themselves (their network

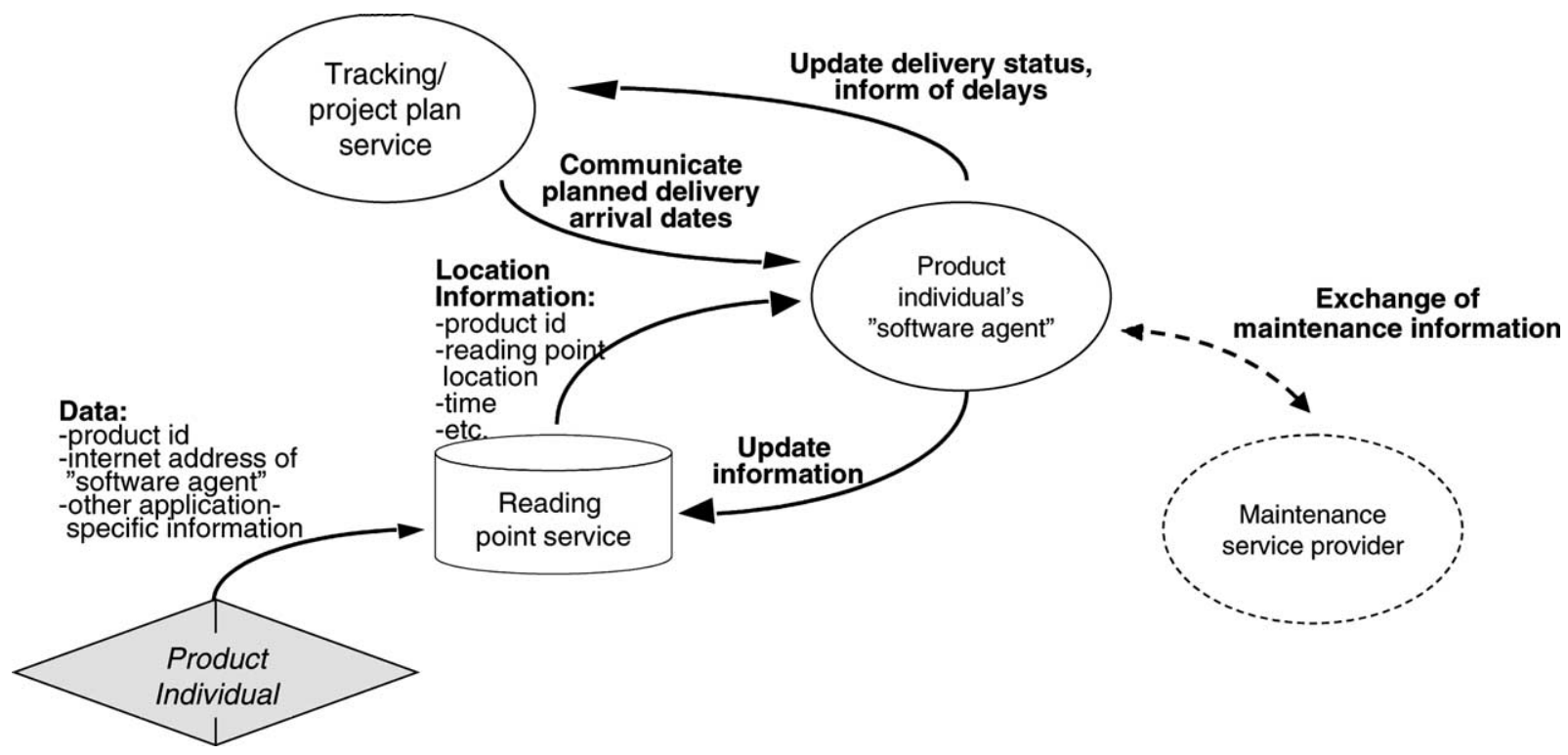

Fig. 2. Information system structure of the peer-to-peer network. 
addresses) is the key to solving the problems in the project delivery chain. It can be used to solve the problem of how to handle effectively a vast number of individualised deliveries, i.e. how to process product individuals through a network of a large number of supply companies, to arrive at the final destination just in time.

Up to now, the handling and information networks of the system have been tested separately. The local handling stations were tested in a classroom implementation of the system. The handling part proved functional. However, in the operational phase, the fact that the tags and readers can come from different suppliers is likely to pose some problems, as the standardisation of RFID technology is not comprehensive.

The distributed program for the peer-to-peer network has also been tested. In the tests, parts of the distributed program were able to bi-directionally change information over the Internet. The parts of the program were able to connect to each other and change information, without any previous information other than the IP-address of the other computer and a public encryption key.

The information system structure enables the solving of the problems of information management and time criticality of the deliveries. The peer-to-peer approach was chosen for the system because it could provide the following advantages:

(a) Low installation overhead

The peer-to-peer network can be easily created by lightweight, downloadable software components that require little or no configuration. This means that new members of the project's supply network can readily be integrated into the architecture.

(b) Equality between parties

All parties of the network remain owners of their own data, so they can define what data they give to whom and when, no matter what size they are.

(c) Scalability

Since no centralised database is needed, there is no need for huge, high-range servers that would quickly become overloaded by global tracking (and other) services. They would also have to be maintained by third-party companies, thus destroying both the "low installation overhead" and "equality between parties" advantages). In a peer-to-peer solution, data is transferred only when needed and stored only as long as it is useful.

(d) Complex centralised optimisation algorithms may be replaced by simple, localised computations [33]

For instance, new shipping routes can be used immediately when new members join the project's supply network, without requiring any updates at the source or destination. Product individuals provide the information needed for processing them, and supply network members focus on their own operation (following the instructions of the product individuals) [10]. This greatly increases the flexibility of the system. Moreover, dynamic changes or disturbances in the state of the logistics network can be taken rapidly into account [34].

In the near future, we will be trying to define open, standard service interfaces for the communication between software components that the distributed software requires. Interfaces can be defined so that the same technical solutions can easily be applied to new problems, like requesting project plan information, maintenance intervals check, etc. This is important in building a comprehensive support system to facilitate information management through the whole life-cycle of the product individual.

Open service interfaces mean that new service providers can dynamically "plug-in" into the logistics services. Standardised software components signify a simple set-up of new services, which make these systems interesting also for smaller companies, which do not have the capability of developing their own system from scratch. This should greatly increase the variety of available information services.

Standardised P2P communication means that existing collaboration and delivery networks between companies can be easily modified. It will no longer be possible for a big company to "tie up" their subcontractors and force them to use only the company's own information systems.

\section{Inside-out control of project deliveries}

Before we move on to analyse how the benefits of low overhead, equality, etc. can be achieved, let us 


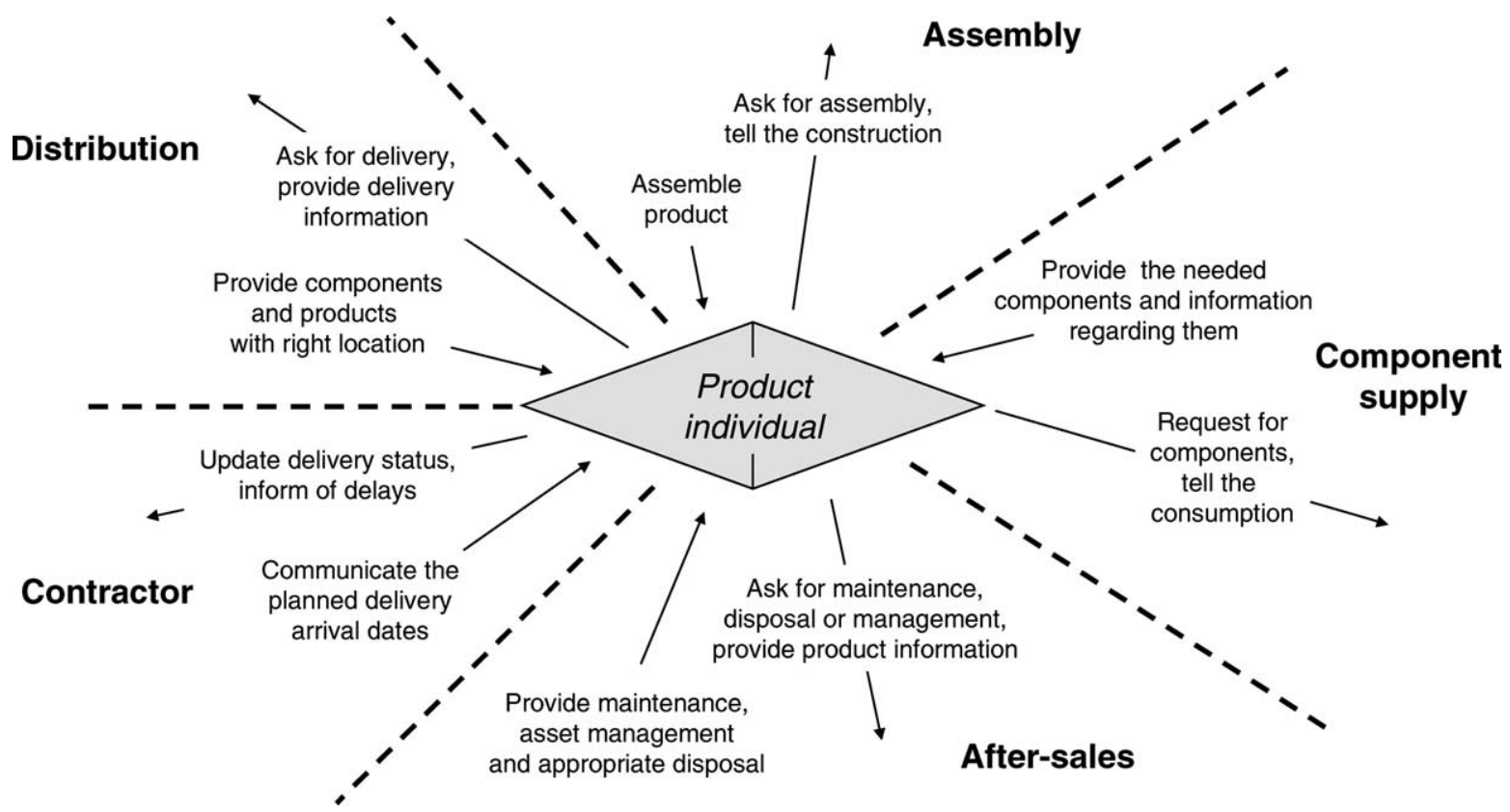

Fig. 3. Inside-out control of project deliveries.

consider an example from the product individual perspective. In this section, the progression of a product individual through its life-cycle is examined in detail to demonstrate the concept of inside-out control from the product individual perspective.

Inside-out control for project deliveries is illustrated in Fig. 3. The arrows originating at the product individual and facing different supply chain phases represent the service requirements the product individual calls upon and the information it offers. The arrows pointing from different supply chain phases to the product individual represent the different logistics services the supply chain phases provide to the product individual.

Now, let us follow the route of a product individual through the supply network, from the very beginning to the usage stage in the completed large investment project.

The product individual is created when the specific object is added to the project plan, and the contractor allocates the delivery to some specific producer. After this, the product individual has its identity and content (in what specification it needs to be delivered, to where, and when), and the individual's identity can be used to control its route to the project site.
In the HUT system, every product individual has its own globally unique identification code. This identification code is used to connect the product individual to information about it. The important point here is that there can be multiple service providers that store information about the product individuals in the network, because the identity of the product individual is the key to information. The identification code is used to store information about the delivery in a way that enables all supply chain members to use the information. This information can be obtained without manual work from the delivery itself by using the identifier, if proper access rights are owned. The safety level of the system is reasonably high, because it is very hard to copy RFID tags, and quite advanced encryption techniques (both with fixed and changing passwords) can be incorporated into the tags and readers ([35], pp. 151-158).

When the project is in the construction phase, the interaction between the product individual and the contractor of the project is very important through the whole supply network. The contractor sets the tempo for the delivery of the product individual by defining the delivery schedule through the project plan. Theproduct individual updates information 
about its progress through the supply network to a tracking service so that the contractor can keep the project plan up to date. The product individual updates its location information whenever it passes a reader belonging to the distributed supply chain information network. The passed-signal from the read-point is instantly sent to the product individual's network address (stored in the tag), which passes information on to the project plan. The location information is also sent to other subscribing network services.

In the component supply phase, the component producers can read the required specifications using the product individual's identity code. Component producers also append the information concerning the product individual to the information regarding the components. The status information is updated directly in the network-address of the product individual, but, for technical specifications and maintenance instructions, referencing can be used. Often the product individual forms a tangled hierarchy, in which a product individual consists of a set of other product individuals [36].

In the assembly phase of the supply chain, the product individual itself asks to be assembled according to the right design specifications, and the assembly plant reacts to the request [10]. The assembly process can be kept simple even though complex products are manufactured, because the information is effectively integrated to the material flow itself. The assembly specifications that were used, and any special information concerning the assembly process are stored in the HUT system, if they should be important in later phases of the product individual's life-cycle. The important point here is that this significantly eases the outsourcing of assembly. As the information needed for assembly can be attained through the product individual, different assembly service providers can be flexibly used [37].

When the product individual is in need of transportation, it asks to be delivered to the customer's defined location from transport service providers belonging to the HUT network. The HUT system automatically provides the necessary information for executing the delivery to the transportation companies [38]. Collaboration in distribution services leads to more effective and adaptable distribution. Transport companies can fulfil the customer needs more effectively and with fewer resources, using co-operative operation models [39]. The success in providing transport services co-operatively lies in the ease of information sharing [40]. Inside-out delivery control facilitates co-operation between transport companies, because when the delivery itself can provide the needed execution information, different distribution services are easier to link.

Inside-out control in after-sales services lets the product individual take a more active role in managing its use. Different after-sales service providers can be more easily used, as the product individual can be used to exchange and synchronise information between the service providers. The needed information, for maintenance, for example, is attainable through the product individual; one does not need to contact the manufacturer. The product individuals also have the capacity to manage their own lifecycle [41]. They are able to ask for maintenance when it is time, and know how they should be disposed when the time comes.

The essential point here is that in the HUT system, the control of the delivery is not arranged through transactions that organisations exchange. Instead, it is controlled by the information that is tied to the material flow itself. This is essential, because anyone possessing a detector, network connections, and eligible equipment to provide service, can handle the delivery. Furthermore, the information is now centralised to the product individual itself. All supply chain members can achieve relevant information through the product individual itself.

\section{Assessment and implementation of inside-out control}

What, then, are the economic benefits of inside-out control in the project delivery chain? The benefits are derived from more efficient and accurate handling, and also from leaner and more effective information connection methods.

The automation of data input reduces error rates significantly. Manual keying of information is generally considered to exhibit an error rate of about 1 in 300 ([42], p. E8). In the difficult environment of a project delivery chain, RFID technology can still increase the reading accuracy and speed over bar coding, which is currently widely used. British Airways, for example, practically eliminated errors in 
baggage sorting with an RFID-based baggage sorting system. It is estimated that airlines could achieve savings of US\$ 6 to 12 billion, with a cost of US\$ 600 million to US\$ 1.2 billion, world-wide [43]. Another good example is LynxExpress, which has been able to build what the company calls a "super-hub" using RIFD technology. The "superhub" is $70 \%$ faster than a conventional hub, significantly more flexible, and virtually error free [44].

The peer-to-peer infrastructure offers three distinct advantages. First, a low installation overhead makes a peer-to-peer system interesting for small companies also. Second, low installation and maintenance overhead together with small computing requirements make the peer-to-peer system easily scalable. Third, all companies have equal power without any consideration for the company's size. These three advantages together also offer substantial economic benefits to companies of all sizes, since they reduce the need for computing power and data storage, as well as the need for IT set-up and maintenance.

The biggest benefits will still come from the interrelation of the effective execution and information management. The actual effort and cost of managing an international project delivery chain are significantly cut, because of more effective material and information flows. This results in better control of the product individuals in the supply network; they are more likely to arrive at the planned time in the desired specification. Also, the project management in itself will be made significantly easier by eliminating unexpected late deliveries, as the tracking service provides the information of a missed delivery date in advance. Also, after the project is completed, aftersales services and re-orders are much easier as the product individual can itself provide information about it.

More detailed quantification of the benefits is important for the further development of the solution outlined in this paper. We have not yet accessed to reliable estimations of the benefits or costs, but are still considering different approaches for modelling and simulating the system.

What then are the cost elements in the system for inside-out control? The costs elements consist of the costs of the information system, and the cost of the identifiers and identification network. The information systems for a distributed solution are quite lean.
Also, maintenance and set-up costs are significantly lower in the distributed system than in other solutions.

Regarding the cost of the identification infrastructure and identifiers, the cost of the identifiers varies greatly, depending on the scale of the system. The cost of tags is between US\$ 0.25 and 1.00 a piece, depending on production volumes [13]. Most optimistic estimations of the current price state it to be US\$ 0.05 , if enough volume for mass manufacturing is achieved [16]. However, in global applications, the cost of the reader network will form the largest cost component [45]. It is therefore important to develop open solutions, so that several supply networks can utilise the same reading points. Thus, the peer-to-peer approach can present significant cost savings over traditional tracking networks.

At this stage, the basic building blocks for the solution have been made and tested separately. What is the roadmap for developing the complete control system going to look like?

In the first phase, the communication between the project contractor and the product individual is arranged. A tracking network that is used to keep the product individuals location information up to date is also built. This is done to ease the strains that the tight arrival timeframe sets on planning the delivery. The second phase of development is the centralising of information management to the product individual itself. Different pieces of information are stored or linked to the HUT system. In the pilot, the information is to be made available by using the identification code of the product individual.

\section{Conclusions}

The project delivery chain poses particularly difficult requirements on logistics control solutions because a high number of subsystems and components needs to be managed as individuals (i.e. they can not be easily substituted without affecting the schedule of the project) through the delivery chain. Transaction based control focuses on what the firms and the organisational units involved need to do to ensure that the materials arrive to the project construction site on time. However, this type of control is inefficient when disruptions occur. For example, tracing an item through the shipping document databases of different 
firms is too a complex and time consuming task when a critical part is missing.

Identity based control simplifies the control task. By linking the control of the material flow directly with the handling of the product individual many benefits can be gained:

The task of setting up a system for tracing, tracking and control is reduced from modifying a large number of existing transaction systems to taking a new system into use in many organisations.

The identity based tracing, tracking and control system is open to new service providers that can extend and improve its functionality without disrupting the operations of the project delivery chain. And, the solution is open, so competing service providers can also emerge. Since the application is based on the principle of looking for further instructions based on the identity of the product individual, different systems and solutions may be used depending on what is needed.

Building the solution is technically feasible today as experiences from the HUT systems project demonstrate. Challenges remain with developing a standard for identification on different levels of product and project organisations.

Research on the wider applicability of the distributed approach to logistics control needs to be carried out in other types of industries. Other high potential application areas that have been identified are the fresh produce delivery chain in the grocery industry and the supply of maintenance, repair and operations supplies in the business-to-business e-commerce environment.

\section{Acknowledgements}

The recent work on developing a flexible control system for global project deliveries is a part of a research initiative focused on developing distributed software applications and operations models to solving the challenges of supply chain management in different industries. The research is funded by Tekesthe national technology agency in Finland-and leading Finnish companies.

\section{References}

[1] K. Artto, R. Heinonen, M. Arenius, V. Kovanen, T. Nyberg, Global Project Business and the Dynamics of Change,
Technology Development Centre Finland and Project Management Association Finland, Helsinki, Finland, 1998, 147 pp.

[2] J. Poskela, Success and Relevant Measures in a Project Delivery Chain, Master's Thesis, Department of Industrial Engineering and Management, Helsinki University of Technology, Espoo, Finland, 2001, 118 pp.

[3] V. Suominen, In Search for A Project Delivery Chain, Master's Thesis, Department of Industrial Engineering and Management, Tampere University of Technology, Tampere, Finland, 2001, 92 pp.

[4] M. Christopher, 1992. Logistics and Supply Chain Management, Pitman, London.

[5] R.B. Johnston, A.K.C. Yap, Two-dimensional bar code as a medium for electronic data interchange, International Journal of Electronic Commerce 3 (1) (1998) 86-101.

[6] D. Levy, Lean production in an international supply chain, Sloan Management Review 38 (2) (1997) 94-101.

[7] R. Pelin, 1996. Handbook of Project Management, Projektihallinnan käsikirja, Projektijohtaminen Ltd., Espoo, 403 pp. (in Finnish).

[8] E.M. Goldratt, 1997. Critical Chain, The North River Press, Massachusetts, 246 pp.

[9] V. Fraza, Ending inventory errors in 60 days, Modern Materials Handling 55 (3) (2000) A11.

[10] T. Feare, Pump up the volume, Modern Materials Handling 55 (3) (2000) 55-59.

[11] I. Töyrylä, 1999. Realising the potential of traceability-a case study research on usage and impacts of product traceability, Finnish Academy of Technology, Espoo.

[12] S. d'Hont, D. Frieden, Radio Frequency Id-The Digital Link to Improved Logistics Management, in: Proceedings of the Conference of Council of Logistics Management, Annual Conference 2000, Council of Logistics Management, New Orleans, 26 September 2000.

[13] L.S. Gould, What you need to know about RFID, automotive manufacturing, Automotive Manufacturing and Production 112 (2) (2000) 46-49.

[14] Philips Semiconductors, Philips I-code product brochure, http://www.semiconductors.com/acrobat/other/identification/ i-code.pdf (visited June 28th 2001), 2000.

[15] Omron, Omron Oy, http://www.omron.fi/ (visited 28 June 2001), 2000.

[16] K. Ashton, Internet Things-MIT, Embedded Technology and the Next Internet Revolution, Tag 2000, Baltic Conventions, The Commonwealth Conference and Events Centre, London, 25 May 2000.

[17] L. Jones, Working without wires, Industrial Distribution 88 (8) (1999) M6-M9.

[18] G. Boxall, The Use of RFID for Retail Supply Chain Logistics, Tag 2000, Baltic Conventions, The Commonwealth Conference and Events Centre, London, 24 May 2000.

[19] T. Lindström, Personal Communication with Timo Lindström from Rafsec Oy, 7 July 2000.

[20] C.A. DeJong, Material handling tunes in, Automotive Manufacturing and Production 110 (7) (1998) 66-69.

[21] AirClic, AirClick Inc., http://www.airclic.com (visited 10 October 2000), 2000. 
[22] M. Ollivier, RFID enhances materials handling, Sensor Review 15 (1) (1995) 36-39.

[23] B. Moore, Bar code or RFID: Which will win the high speed sortation race? Automatic ID News 15 (7) (1999) 29-30, 34 and 36.

[24] Anon, Bar codes meet RFID, Logistics Management and Distribution Report 38 (10) (1999) A17.

[25] Bluetooth, Bluetooth Special Interest Group http://www.bluetooth.com (visited 29 January 2001), 2001

[26] D. Deckmyn, Bluetooth, Computerworld 34 (24) (2000) 73.

[27] A. Stirpe, Vendors sink their teeth into Bluetooth, Computer Reseller News 8 (870) (1999) 2.

[28] J. Burnell, Big air! Three more RFID standards proposed, Frontline Solutions 1 (8) (2000a) 50.

[29] Anon, RFID makers submit standards plan to ISO, Logistics Management and Distribution Report 39 (5) (2000) 81.

[30] S. Oaks, H. Wong, Jini in a nutshell: a desktop quick reference, O'Reilly and Associates, Sebastopol, CA, 2000.

[31] Sun Microsystems, RMI Specification, on-line address: http:// java.sun.com/products/jdk/1.2/docs/guide/rmi/spec/rmiTOC.doc.html (visited last 28 June 2001), 1998.

[32] R. Orfali, D. Harkey, J. Edwards, Instant CORBA, Wiley, New York, 1997.

[33] E. Bonabeau, C. Meyer, Swarm intelligence: a whole new way to think about business, Harvard Business Review 79 (5) (2001) 106-114.

[34] H.V. Brussel, L. Bongaerts, J. Wyns, P. Valckenaers, T.V. Ginderachter, A conceptual framework for holonic manufac- turing: identification of manufacturing holons, Journal of Manufacturing systems 18 (1) (1999) 35-52.

[35] K. Finkenzeller, RFID Handbook, Wiley, West Sussex, 2000.

[36] D.R. Hofstadter, An Eternal Golden Braid, A Metaphorical Fugue on Minds and Machines in the Spirit of Lewis Carroll, Penguin, Harmondsworth, 1980.

[37] M. Kärkkäinen, J. Holmström, Wireless item identification: a solution for e-commerce fulfilment problems, International Journal of Electronic Business, 2001, in press.

[38] Anon, RFID deliver for baggage service start-up, Frontline Solutions 1 (12) (2000) 8.

[39] J. Narus, J. Anderson, Rethinking distribution: adaptive channels, Harvard Business Review 74 (4) (1996) 112-120.

[40] T. Gormley, B. Cameron, Extend for collaboration, Manufacturing Systems 16 (7) (1998) 20.

[41] V. Thomas, W. Neckel, S. Wagner, in: Proceedings of the 1999 IEEE International Symposium on Information technology and product lifecycle management, Electronics and the Environment, Danvers, MA, USA, 1999, pp. 54-57.

[42] Anon, AIM Buyers guide 2000-2001, Automatic Identification Manufacturers, 2000.

[43] D.W. Nelms, Move forward on RFID, Air Transport World 2 (3) (1999) 2.

[44] Anon, Money well spent, Frontline Solutions 1 (6) (2000) $30-31,59$.

[45] K. Hickey, A diamond in the rough, Traffic World 258 (5) (1999) 30-34. 